\title{
Assessing excess mortality in Vienna and Austria after the first year of the COVID-19 pandemic
}

\author{
Ramon Bauer $^{1}$, Markus Speringer ${ }^{1, *}$, Peter Frühwirt ${ }^{2}$, Roman Seidl ${ }^{2}$ \\ and Franz Trautinger ${ }^{1}$
}

\section{Abstract}

In Austria, the first confirmed COVID-19 death occurred in early March 2020. Since then, the question as to whether and, if so, to what extent the COVID-19 pandemic has increased overall mortality has been raised in the public and academic discourse. In an effort to answer this question, Statistics Vienna (City of Vienna, Department for Economic Affairs, Labour and Statistics) has evaluated the weekly mortality trends in Vienna, and compared them to the trends in other Austrian provinces. For our analysis, we draw on data from Statistics Austria and the Austrian Agency for Health and Food Safety (AGES), which are published along with data on the actual and the expected weekly numbers of deaths via the Vienna Mortality Monitoring website. Based on the definition of excess mortality as the actual number of reported deaths from all causes minus the expected number of deaths, we calculate the weekly prediction intervals of the expected number of deaths for two age groups ( 0 to 64 years and 65 years and older). The temporal scope of the analysis covers not only the current COVID-19 pandemic, but also previous flu seasons and summer heat waves. The results show the actual weekly numbers of deaths and the corresponding prediction intervals for Vienna and the other Austrian provinces since 2007. Our analysis underlines the importance of comparing time series of COVID-19-related excess deaths at the sub-national level in order to highlight within-country heterogeneities.

Keywords: mortality; excess mortality; COVID-19; regional analysis; Austria

\footnotetext{
${ }^{1}$ Statistics Vienna at the City of Vienna's Department for Economic Affairs, Labour and Statistics (MA 23), Vienna, Austria

${ }^{2}$ Basic Research Section at the City of Vienna's Department for Economic Affairs, Labour and Statistics (MA 23), Vienna, Austria

*Correspondence to: Markus Speringer, markus.speringer@wien.gv.at
} 


\section{Introduction}

In Vienna, the first coronavirus infection case was reported on 26 February 2020. The first COVID-19-related death in Austria was registered a week later (5 March 2020) in the province of Tyrol. More than one and a half years later (at the end of August 2021), the total number of reported cases of COVID-19 in Austria was over 700,000 , despite the implementation of public health measures aimed at limiting the spread of the disease (i.e., physical and social distancing, lockdowns, curfews, mask mandates etc.) (AGES, 2021a). ${ }^{1}$ Moreover, it is broadly assumed that the number of undetected cases is many times higher (Roser et al., 2020; Statistik Austria, 2020a). By the end of August 2021 (week 34-2021), or just over a year and a half after the first death from COVID-19 occurred in Austria, the official number of COVID-19related deaths in Vienna and in Austria had surpassed 2,000 and 10,000, respectively (AGES, 2021a).

According to the German Robert Koch Institute (RKI, 2021), COVID-19 has an incubation time of five to six days, and there is usually a lag of several days before the results of COVID-19 tests are included in the official statistics. In general, it is assumed that changes in social behaviour, which might or might not be triggered by various government-imposed measures, are reflected in the official case count with a lag of 10 to 14 days; and that deaths from COVID-19 usually occur within four weeks of the initial infection (Nivette et al., 2021; RKI, 2021).

During the first one and a half years of the pandemic, ${ }^{2}$ the number of reported COVID-19 infections in Austria had already peaked three times: the first wave was in March 2020; the second wave was in autumn/winter 2020/21; and the third wave started in February 2021, and lasted until the end of May 2021. Since the beginning of August 2021, the number of COVID-19 cases has again been rising, marking the start of a fourth wave, the full extent of which will only become apparent in the coming weeks and months (see Figure 1).

However, when analysing COVID-19-related deaths, it is important to keep in mind that the reporting of COVID-19 as a cause of death could be inaccurate or subject to undercounting (Aron et al., 2020). This was especially likely to be the case during the early phases of the pandemic, when reliable tests were not yet widely available, or were simply not administered across the board. It is, for instance, probable that many people who died while infected with COVID-19 were never tested for the virus (The Economist, 2021). Yet it is also likely that as testing has increased sharply since the onset of the pandemic, cases

1 Data retrieved on 6 May 2021 from the Austrian COVID-19 dashboard, provided by AGES/Federal Ministry of Social Affairs, Health, Care and Consumer Protection: https://covid19-dashboard.ages.at/.

2 On 11 March 2020, the WHO Director General declared COVID-19 a pandemic (WHO, 2020). A pandemic is loosely defined as an "(...) epidemic occurring over a very wide area, crossing international boundaries and usually affecting a large number of people" (Porta, 2014, p. 209). Despite fitting this definition, seasonal epidemics like influenza ("flu") are normally not considered pandemics (Kelly, 2011; WHO, 2013, 2021a). 
Figure 1:

Number of reported COVID-19 cases per day (per 100,000 inhabitants) in Vienna and Austria since week 1-2020

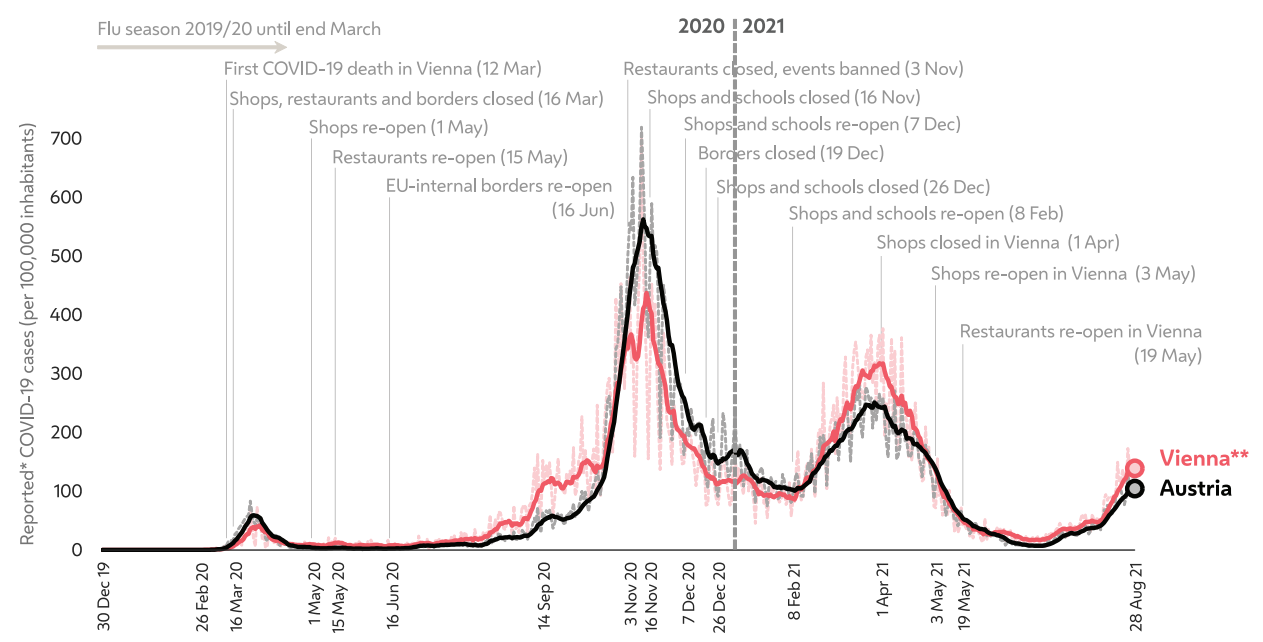

Notes: *Please note that there is a 10- to 14-day lag between the time of infection and the reporting date shown in the chart. ${ }^{* *}$ The dotted line shows the daily reported cases, and the solid line shows the seven-day average per 100,000 inhabitants.

Data Source: AGES (2021a) and own calculations.

of people who have died of causes other than COVID-19 (e.g., from car accidents), but who tested positive for the virus, might have contributed to a certain degree of over-reporting of COVID-19-related deaths; i.e., some deaths may have been misclassified in the official statistics as deaths from COVID-19 (CDC, 2021) if it was unclear whether these individuals died because of COVID-19 or simply while infected with COVID-19. Furthermore, voluntary and government-mandated changes in behaviour may have influenced the number of infections and deaths. Since March 2020, people living in Vienna, across Austria and in many other parts of the world have been travelling and commuting less than they did previously (because of remote work orders, social distancing mandates, bans on events and border closures), which should have led to fewer human interactions (Google LLC, 2021; Ritchie et al., 2021; Statistics Vienna, 2021a). Reductions in mobility and in personal interactions might have contributed, for example, to reductions in traffic accidents/fatalities (Statistik Austria, 2020b) ${ }^{3}$ or influenza infections (City of Vienna Health Service, 2021). At the same time, however, the incidence of

\footnotetext{
3 In the first half of 2020, the number of traffic accidents, injuries and fatalities was almost $25 \%$ lower than it was in the corresponding reference period in 2019 (Statistik Austria, 2020b). Nevertheless, out of all deaths, the share that is attributable to traffic accidents is relatively small.
} 
household accidents (ORF, 2021a), domestic violence (especially against women) (ORF, 2021b) or suicides might have increased (Prlić, 2021). Additionally, people with health conditions (e.g., cancer) might have deliberately postponed necessary treatments at medical facilities due to concerns about safety, or they may have been unable to access care if the health system was overwhelmed by COVID-19 cases, or if providers decided to prioritise patients with COVID-19 over those with other symptoms (CDC, 2021; The Economist, 2021). For these reasons, mortality due to non-COVID-19-related causes of death, like cancer, respiratory diseases and circulatory diseases, may have increased over the course of the pandemic (Aron et al., 2020).

All of these factors complicate our efforts to answer the question of whether and, if so, when and to what extent the COVID-19 pandemic has led to an increase in the number of deaths; i.e., to excess mortality. By definition, excess mortality is the number of deaths from all causes in a given period relative to the number of deaths that would have normally been expected to occur in that period. For assessing the direct and indirect impacts of COVID-19 on overall mortality, excess mortality for all causes of deaths is a well-established indicator (Aburto et al., 2021; Aron et al., 2020; Ghislandi et al., 2021; Schöley, 2021).

Since June 2020, and based on the concept of excess mortality, Statistics Vienna has been monitoring and evaluating the weekly mortality trends in Vienna and in other Austrian provinces (Bauer et al., 2021a, 2021b; Statistics Vienna, 2021b), as well as in selected European cities (Statistics Vienna, 2021c). In this paper, we aim to quantify the impact of COVID-19 on the overall mortality level (all causes) in Vienna and in other provinces of Austria, and to examine to what extent the number of reported COVID-19 deaths corresponds to the overall mortality level during the first year of the pandemic; i.e., from week 1-2020 to the end of August 2021 (week 34-2021). In the following sections, we briefly describe our methodological approach (Section 2), and then present our findings (Section 3), as well as a discussion of the results (Section 4).

\section{Data and methods}

In order to assess whether there was any excess mortality, and, if so, to what extent it deviated from "normal" mortality, it is necessary to define the "expected" number of deaths based on mortality trends observed in the (recent) past. In this section, we briefly explain the required input data and the basic principles that underlie our excess mortality model, but without going in too much detail, as the methodology is well documented in Bauer et al. (2021a, 2021b) and in Frühwirt and Seidl (2020).

In general, we seek to quantify the range of the expected weekly number of deaths. For this reason, we have defined prediction intervals ("bands") comprising $99 \%$ of the expected values, while assuming a random and independent distribution of the weekly number of deaths for two broad age groups ( 0 to 64 years and 65 years and 
older). ${ }^{4}$ These "bands" take into account seasonal fluctuations (caused, for example, by summer heat waves or winter flu epidemics) and changes in population size, age structure and life expectancy (BFS, 2020a, 2020b; Frühwirt and Seidl, 2020). Based on these prediction intervals, all values of weekly deaths exceeding the upper limit of the defined range (i.e., "bands") are classified as excess mortality.

\subsection{Data}

In our excess mortality model, which was developed for the Vienna Mortality Monitoring project (Bauer et al., 2021a) ${ }^{5}$ to quantify the impact of COVID-19 on overall mortality, we use data from the Austrian Population Register (POPREG) and from the Register of Vital Statistics (ZPR) provided by Statistik Austria (Statistik Austria, 2021a,b):

\section{- Input Data}

- Population (at the beginning of the year) by 1-year age groups and Austrian provinces, 2002-2021 (Statistik Austria, 2021a)

- The number of daily deaths (date of death) by 1-year age groups for all causes of death in the Austrian provinces, 2002-2019 (Statistik Austria, 2021b)

\section{- Output Data ${ }^{6}$}

- The predicted weekly number of deaths and the prediction interval (by calendar week) for two broad age groups (0 to 64 years, 65 years and older) for all causes of death in the Austrian provinces, 2007-2021 (Statistics Vienna, 2021d), and

\footnotetext{
4 At the time of the analysis, more detailed mortality data by one-year age groups were only available for the years 2002 until 2019. The 2020 data were only recently published (in summer 2021), and were not used to calculate the "bands", as COVID-19 deaths had already biased mortality behaviour. Additionally, our aim was to show how the reported number of deaths during the pandemic might have deviated from the expected number of deaths. As more recent weekly data have been published only for the broader age groups 0 to 64 years and 65 years and older, a more age-detailed estimation of mortality bands is currently not possible.

5 The methodological approach behind the model is based on the methodology introduced by the Federal Statistical Offices, Switzerland (BFS, 2020a).

6 At the time of the final submission of this paper, the data for 2021 were available up to calendar week 34-2021 (i.e., the week of Monday, 23 August to Sunday, 28 August 2021).
} 
- The corresponding weekly number of deaths (by calendar week) for two broad age groups ( 0 to 64 years, 65 years and older) for all causes of death in the Austrian provinces, 2007-2021 (Statistik Austria, 2021c) ${ }^{7}$

The temporal scope of this paper focuses on a weekly analysis of excess mortality during the period of January 2020 (week 1-2020) to August 2021 (week 34-2021), based on the weekly number of deaths (from all causes) during the reference period of 2015 to 2019. All deaths of people with a residence in Austria and who died in Austria during these periods are included in the analysis.

\subsection{Excess mortality model}

To assess whether there has been any excess mortality in Austria's provinces during the COVID-19 pandemic, it is necessary to determine the expected and the normal weekly number of deaths in order to calculate the respective confidence intervals ("bands"). The prediction intervals comprise $99 \%$ of the expected values assuming a random and independent distribution of the weekly number of deaths for two broad age groups: 0 to 64 years and 65 years and older (BFS, 2020a, b; Frühwirt and Seidl, 2020).

The expected number of deaths is estimated based on mortality data from the previous five-year period. In our analysis of excess mortality, we used the 2015 to 2019 reference period for both years of the pandemic: i.e., 2020 and 2021. Since the COVID-19 pandemic definitely affected mortality in 2020, we have decided not to shift to the 2016 to 2020 reference period for the calculation of excess mortality in 2021, but to instead use the 2015 to 2019 reference period for 2021 as well. Based on the available data from the Austrian register of vital statistics (ZPR), which date back to 2002, we are able to calculate expected mortality and excess mortality dating back to 2007 (starting with the 2002 to 2006 reference period). The calculation of the expected number of deaths and bandwidth is based on the reported weekly number of deaths in the respective previous five years.

Our calculation of the expected weekly mortality for the year of analysis is based on the methodological approach developed by our Swiss colleagues from the Federal Statistical Office, Switzerland (BFS, 2020a,b), and takes two elements into consideration: the expected number of deaths for the year of analysis by age group and seasonality; i.e., how those deaths are distributed across the weeks of the year. Both elements are calculated based on the median of the weighted weekly number of deaths by age group for the reference period.

\footnotetext{
7 These data are not used in the model, but they are used in the visualisation of the data in Section 3 . Please note that the number of deaths in the two latest available weeks have not yet been fully registered, and are therefore only partially estimated by Statistics Austria. Data on weekly deaths since 2007 in Austria at the scale of provinces (NUTS 2), as well as the prediction intervals, are published at the Austrian Open Data portal: https://www.data.gv.at/katalog/dataset/feaddbdf-ed07-4c37-818adb63447d5567.
} 
In the first step, we convert the calendar weeks of our base year 2020 into ISO weeks (ISO, 2019a, 2019b) $)^{8}$ to retrieve a date sequence ${ }^{9}$ that is applied to all reference years in order to obtain standardised week units. Standardising all years to the same number of calendar weeks and days ensures the comparability of the findings across all years included in the analysis.

In the next step, the daily numbers of deaths by one-year age groups (Statistik Austria, 2021b) are allocated to the recoded (calendar) weeks for each reference year. Those weekly deaths are weighted by the population size by age and sex in the respective reference years in order to obtain a ratio that can be used to estimate an age- and life expectancy ${ }^{10}$-adjusted expected number of deaths in 2020 and in 2021 (Frühwirt and Seidl, 2020).

The seasonality effects of mortality for both age groups ( 0 to 64 years and 65 years and older) make it necessary to calculate the median of the weighted weekly number of deaths by age group for every week of the reference years. Those weekly median values represent the expected seasonal values for the calendar weeks in the year of analysis for each age group. At this point, seasonality is smoothed using a local regression method (Locally Estimated Scatterplot Smoothing regression, LOESS) and extrapolated to derive the expected annual and weekly numbers of deaths in 2020 and 2021. In the last step, we apply a Poisson prediction interval of $99 \%$ to the expected number of deaths per week and age group to obtain a "band" that reflects the "normal" mortality range, which we can then use to detect the excess mortality - or even the mortality deficits - for each week.

\section{Findings}

A comparison of the weekly numbers of deaths in Vienna and Austria over our study period reveals the exceptional nature of the mortality patterns in 2020 and 2021. While taking into account that the risk of dying from a COVID-19 infection is considerably higher for older than for younger people (Mallapatty, 2020), Figure 2 shows the weekly number of deaths among the population aged 65 and older since 2007 (until week 34-2021). The visualisation depicts seasonal patterns and peaks of higher mortality during winter flu epidemics and summer heat waves. The years of

\footnotetext{
8 An International Organization for Standardization (ISO) year contains of 52 or 53 full ISO weeks with 364 or 371 days that can leap into the previous and the following year. Each week has a day sequence from Monday to Sunday ISO weeks follow a leap week calendar system (ISO, 2019a, 2019b). 9 The basic date sequence for the ISO year 2020 runs from Monday, 30 December 2019 to Sunday, 3 January 2021.

10 Since 2002, life expectancy at birth for both men and women has, on average, increased by about two months per year. However, due to COVID-19 pandemic, life expectancy at birth in Austria dropped by seven months for men and by six months for women between 2019 and 2020. In Vienna, these declines were even larger, as life expectancy at birth decreased over this period by more than 8.5 months for men and by about eight months for women (Statistik Austria, 2021d).
} 
Figure 2:

Weekly numbers of deaths (all causes) in the age group 65 and older in Vienna and Austria since week 1-2007
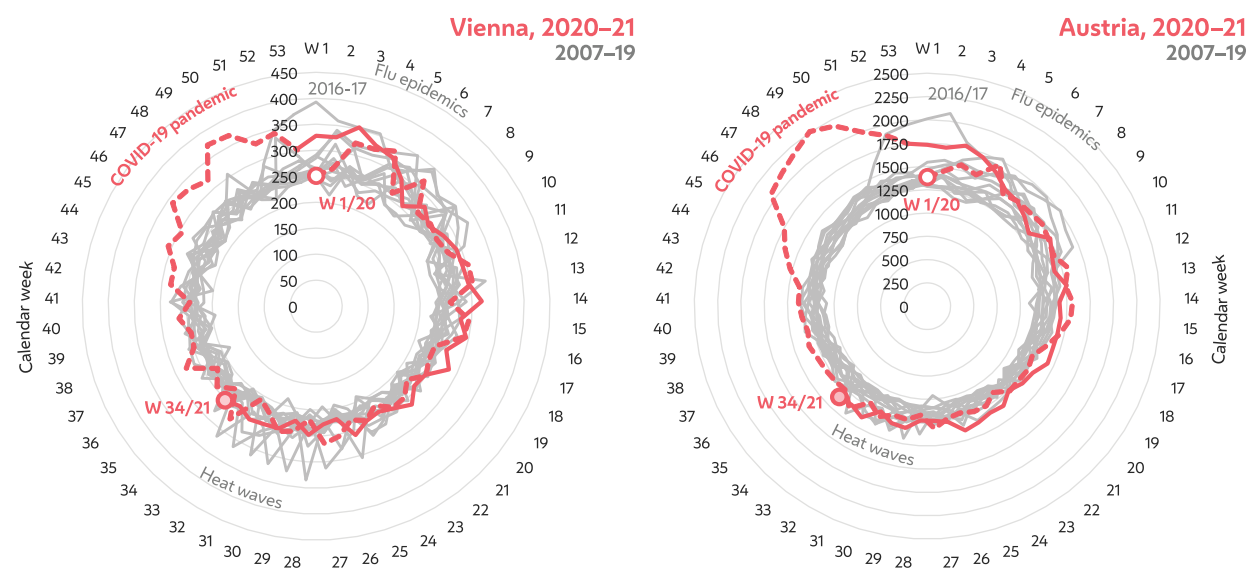

Data Source: Statistik Austria (2021c) and own calculations.

the coronavirus pandemic (i.e., 2020 and 2021) are highlighted in red. The results indicate that the weekly number of deaths increased noticeably for the first time in March and April 2020 (between week 12-2020 and week 18-2020). After a period of relatively normal mortality levels during the summer of 2020, the weekly numbers of deaths in Vienna and Austria again rose sharply starting at the end of September (from week 40-2020 onwards), and then returned to normal levels during the early weeks of 2021. The numbers of registered cases increased again in February 2021, but had flattened by the end of August (i.e., week 34-2021, which also marks the end of the temporal scope of this analysis). However, this third wave of infections did not result in the large increases in weekly mortality that had been reported during the second wave in the latter months of 2020. A similar pattern could be observed in summer 2021, when the numbers of infections again started to increase.

A descriptive comparison of the weekly numbers of deaths (as shown in Figure 2) allows us to quantify the deviation of the weekly numbers of deaths from the numbers of deaths in the corresponding weeks in previous years (usually the most recent five years; see, for example, Destatis, 2021; EuroMOMO, 2021; Eurostat, 2021; or Giattino et al., 2021), but usually does not consider changes in population size and age structure, which, in turn, affect the actual numbers of deaths. In order to quantify the impact of COVID-19 on overall mortality (all causes) in Vienna and in other provinces of Austria, we apply our model that takes into account not only changes in the seasonality of mortality, but also changes in population size and age structure with respect to the reference period (cf. Section 2.1). 
Figure 3:

Numbers of deaths and expected range per week and age group in Vienna since week 1-2007

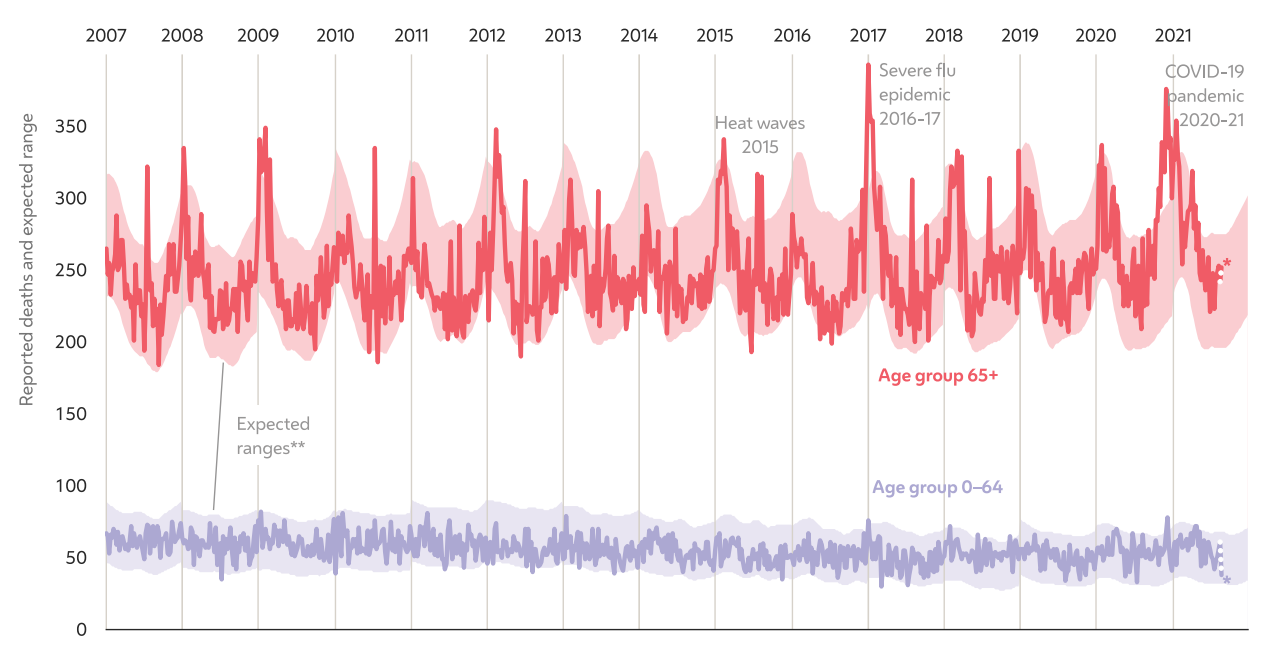

Notes: *Data for the two most recent weeks are partially estimated (dotted). ${ }^{* *} 99 \%$ prediction interval. Data Source: Statistik Austria (2021c) and own calculations.

Figure 3 shows the weekly numbers of deaths in the age groups 0 to 64 years (blue) and 65 years and older (red), as well as the expected range of the weekly numbers of deaths since 2007 in Vienna in the respective age groups. These longer time series, which extend beyond the COVID-19 pandemic period, demonstrate that periods of excess mortality - i.e., when the data points exceed the range of expected values - are not at all unusual. Some seasonal events, like extreme heat waves (during the summers of 2010, 2012, 2015 and 2018) and severe flu epidemics (e.g., during the winter of 2016/2017), have caused excess mortality among the elderly population in Vienna and Austria in the recent past. While the durations of such seasonal events were generally relatively short (i.e., a few weeks), the COVID-19 pandemic caused a considerably longer period of continuous excess mortality among people aged 65 years and older that lasted several months. In Austria as a whole, this period lasted from mid-October 2020 (week 43-2020) until the end of January 2021 (week 4-2021) (see also Figure 5).

According to AGES (2021a), more than 10,000 COVID-19-related deaths were registered in Austria until the end of August 2021 (week 34-2021). Overall, approximately $7.2 \%$ of all people who died in Austria between week 1-2020 and week 34-2021 were diagnosed with COVID-19. The provinces with the highest shares of COVID-19-related deaths were Styria (9.1\%) and Vienna (8.3\%), while the provinces with the lowest shares of COVID-19-related deaths were Vorarlberg (5.8\%), Burgenland (5.7\%) and Lower Austria (5.5\%) 
Figure 4:

Number of reported COVID-19 deaths per week (per 100,000 inhabitants) in Austria's provinces since week 1-2020

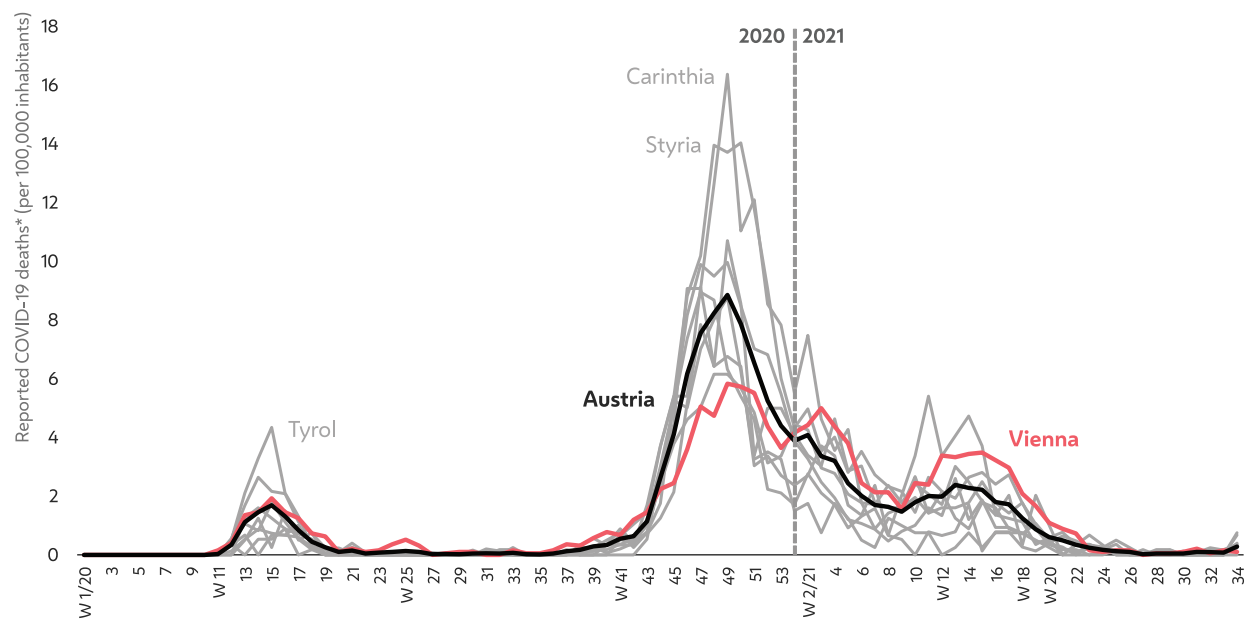

Notes: *COVID-19 deaths are reported by date of death. Data Source: AGES (2021a) and own calculations.

(AGES, 2021a; Statistik Austria, 2021c). To contextualise the overall mortality levels, Figure 4 illustrates the weekly numbers of COVID-19 deaths per 100,000 inhabitants in Austria and its nine provinces. The province of Tyrol was hit especially hard by COVID-19-related deaths during the first wave of infections (in March and April 2020). However, during the second wave (in the autumn and winter in 2020/2021), the provinces with the highest relative numbers of COVID-19-related fatalities were Carinthia and Styria. The third wave of infections, which peaked in March 2021, resulted in fewer reported COVID-19 cases and deaths than the second wave (see Figure 1 and Figure 4). However, in the third wave, the number of COVID19-related intensive care unit (ICU) admissions was similar to that in the second wave. COVID-19 vaccination started at the beginning of 2021 for the oldest age groups. By the end of August 2021 (week 34-2021), more than 5.5 million (69.7\%) of the population aged 12 years and older and 1.5 million (87.5\%) of the population aged 65 years and older in Austria had received at least one shot of a COVID-19 vaccine (BMSGPK, 2021). This high vaccination rate contributed to the reduction in the number of deaths among people aged 65 and older during the third wave of infections (in the spring of 2021).

Focusing on excess mortality (all causes) during the COVID-19 pandemic (i.e., in 2020 and 2021), Figure 5 and Figure 6 show the weekly numbers of deaths in 


\section{Figure 5:}

Numbers of deaths and expected range** per week and age group in Austria since week 1-2020

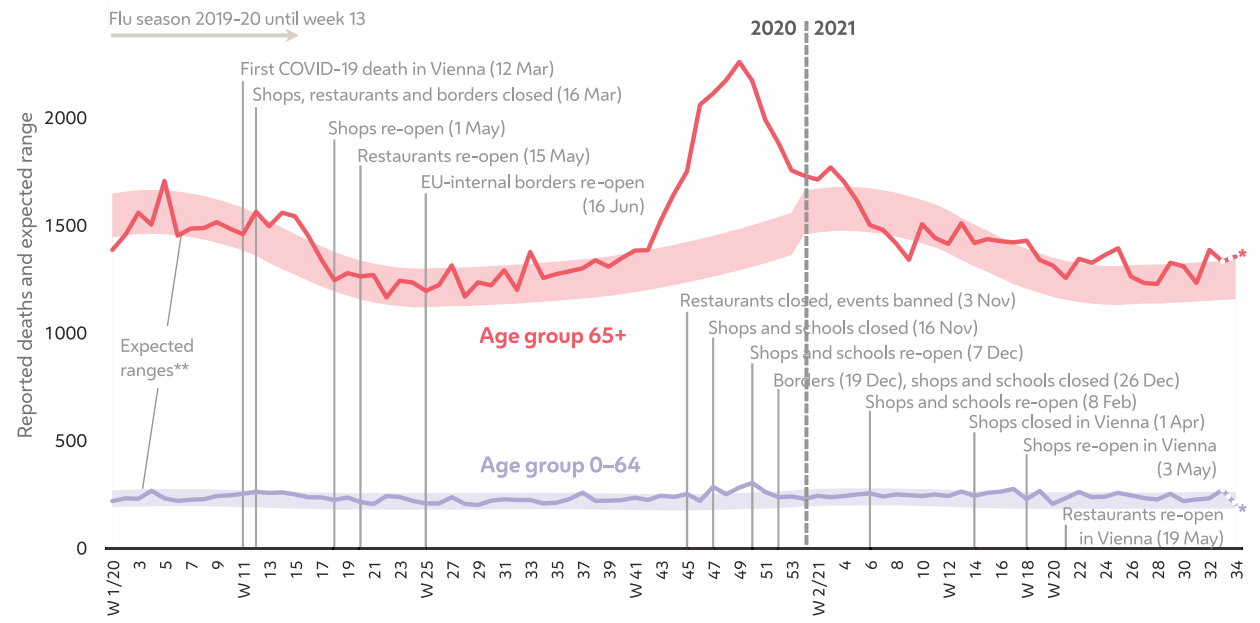

Notes: *Preliminary data: Data for the two most recent weeks partially estimated (dotted). ${ }^{* *} 99 \%$ prediction interval. Please note that there is a three- to four-week lag between the point in time when individuals are infected with SARS-CoV-2, and the time of death.

Data Source: Statistik Austria (2021c) and own calculations.

the 0 to 64 years and 65 years and older age groups in Austria and Vienna. ${ }^{11}$ The visualisations clearly depict the weeks and periods with prevailing excess mortality - i.e., when the data points exceeded the upper range of the expected values. Almost all of the excess mortality can be observed among the population aged 65 years and older, while almost no quantifiable excess mortality can be detected among the population under age 65 years (with the exception of a few weeks in late 2020). In general, it appears that the patterns of excess mortality in Austria and Vienna were largely in line with the timing and the extent of the respective peaks. It should be noted that since the population of Vienna accounts for $21 \%$ of the Austrian population (at the beginning of 2021), the mortality trends in Vienna have a substantial impact on the overall mortality levels in Austria.

11 Why do prediction bands "jump" at the turn of the year? At the turn of the year 2020 to 2021, the prediction bands in the visualisations "jump up". This is partly because estimated mortality tends to increase in January due to seasonal flu epidemics. Above all, the "jump" is a statistical artefact: the prediction bands are (among other factors) based on the population size and the age structure on 1 January of the respective year, and are then smoothed over this period. At the turn of the year, these parameters and the reference period for smoothing change. Hence, the prediction bands appear to "jump". 
Figure 6:

Numbers of deaths and expected range ${ }^{* *}$ per week and age group in Vienna since week 1-2020

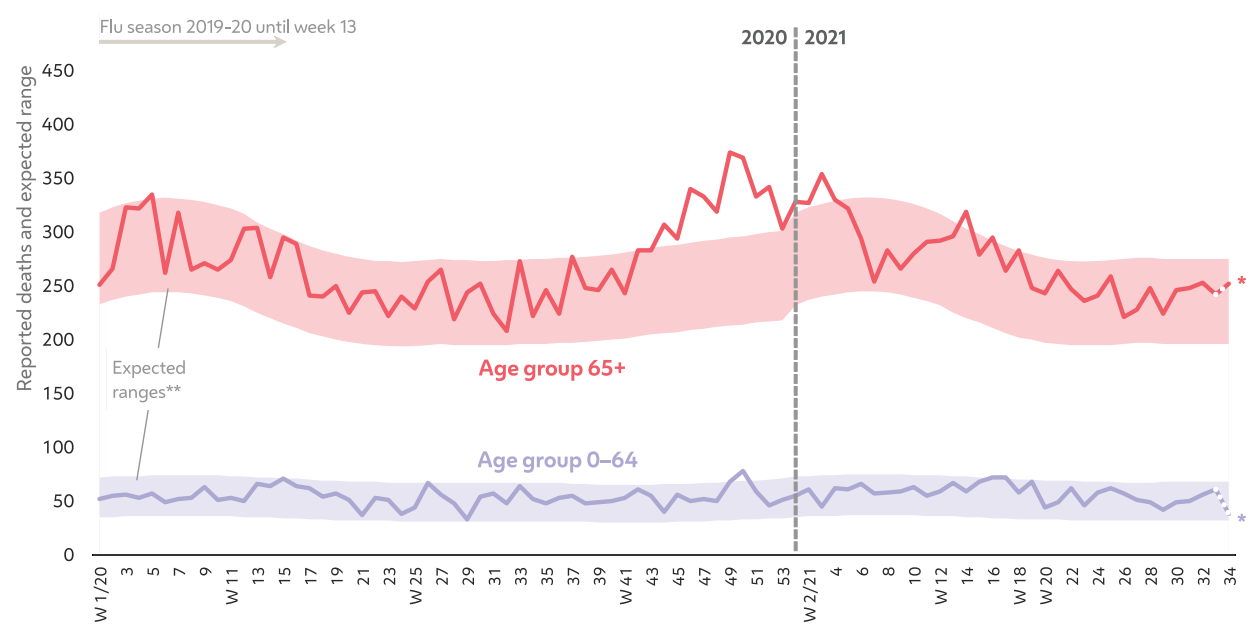

Notes: *Preliminary data: Data for the two most recent weeks partially estimated (dotted). ${ }^{* *} 99 \%$ prediction interval. Please note that there is a three- to four-week lag between the point in time when individuals are infected with SARS-CoV-2, and the time of death.

Data Source: Statistik Austria (2021c) and own calculations.

A comparison of Figure 5 (Austria) and Figure 6 (Vienna) demonstrates another effect related to population size. As we described in Section 2.2 (Excess Mortality Model), the higher number of deaths (events) that occurred in Austria compared to in Vienna (and other provinces) affects the range of the expected values. The population size determines the width of the prediction interval, and, thus, how clearly excess mortality can be assessed. The larger the population and, hence, the larger the numbers of corresponding deaths, the narrower the expected variance in the weekly numbers of deaths is, and, in turn, the narrower the width of the prediction intervals is. Ultimately, a larger number of events (deaths) allows for a more precise assessment of excess mortality. When interpreting the ranges of the expected values of the weekly numbers of deaths by age group, it should be taken into account that the prediction intervals cannot be used to directly compare events and trends in regions with different population sizes. Instead, the prediction intervals show how accurately (with respect to statistical significance) excess mortality is assessed for the respective week in the respective region.

In order to assess to what extent the numbers of COVID-19 deaths correspond to the identified excess mortality, we compare the weekly numbers of reported COVID-19 deaths with the deviation from the median expected weekly numbers of deaths in 2020 and 2021 in Austria (Figure 7). The results indicate that overall, the number of COVID-19-related fatalities corresponds quite well to the deviations 


\section{Figure 7:}

Numbers of reported COVID-19 deaths (columns) and the deviation of the numbers of deaths from the expected values (line) in Austria since week 1-2020

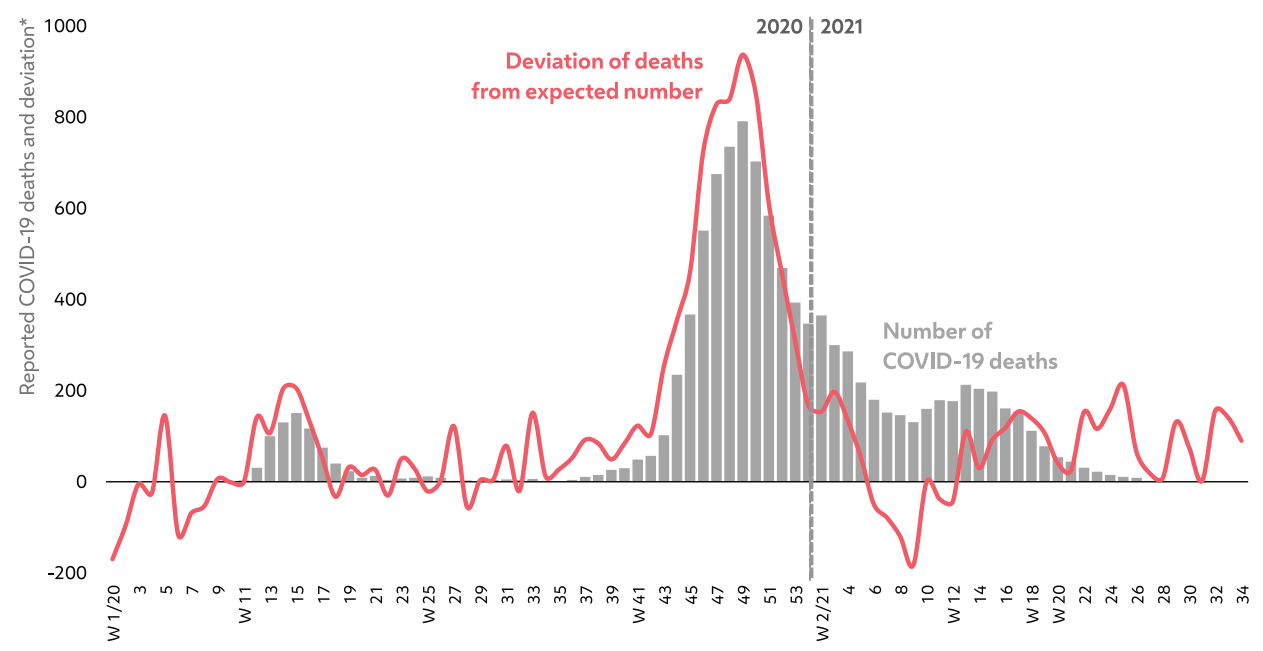

Notes: *Numbers of COVID-19 deaths (columns) and the deviation of the numbers of deaths from the expected values (line).

Data Source: AGES (2021a) and own calculations.

in overall weekly mortality (based on our excess mortality model). This nationwide pattern also appears to reflect the developments in Vienna and in other provinces of Austria during the first year of the COVID-19 pandemic. $^{12}$

The observed positive deviations of the actual weekly numbers of deaths from the median of the range of the expected numbers of deaths during the first weeks of 2020 and the summer months in 2020 and 2021 (as shown in Figure 7) can be attributed to the annual flu season and heat waves in Austria during the 20152019 reference period (as shown in Figure 3). Generally, the findings indicate that the calculation of the range of expected values is highly influenced by seasonal events, like flu epidemics during the winter months or extreme heat waves during the summer months in the respective reference periods.

The first COVID-19 deaths in Austria and Vienna were reported in week 11-2020. A week later, the first nationwide lockdown went into effect in Austria, and the

12 For Austria as a whole, the numbers of COVID-19-related deaths seem to match the deviations in weekly mortality more clearly than they do for Vienna and other provinces of Austria. This might be attributed to the smaller numbers of people (and of events) at the level of provinces, which may, in turn, result in more (short-term) fluctuations and variations in such high frequency indicators as the weekly number of deaths. 
Figure 8:

Estimated numbers of influenza and flu-like infections per week in Vienna since 2015

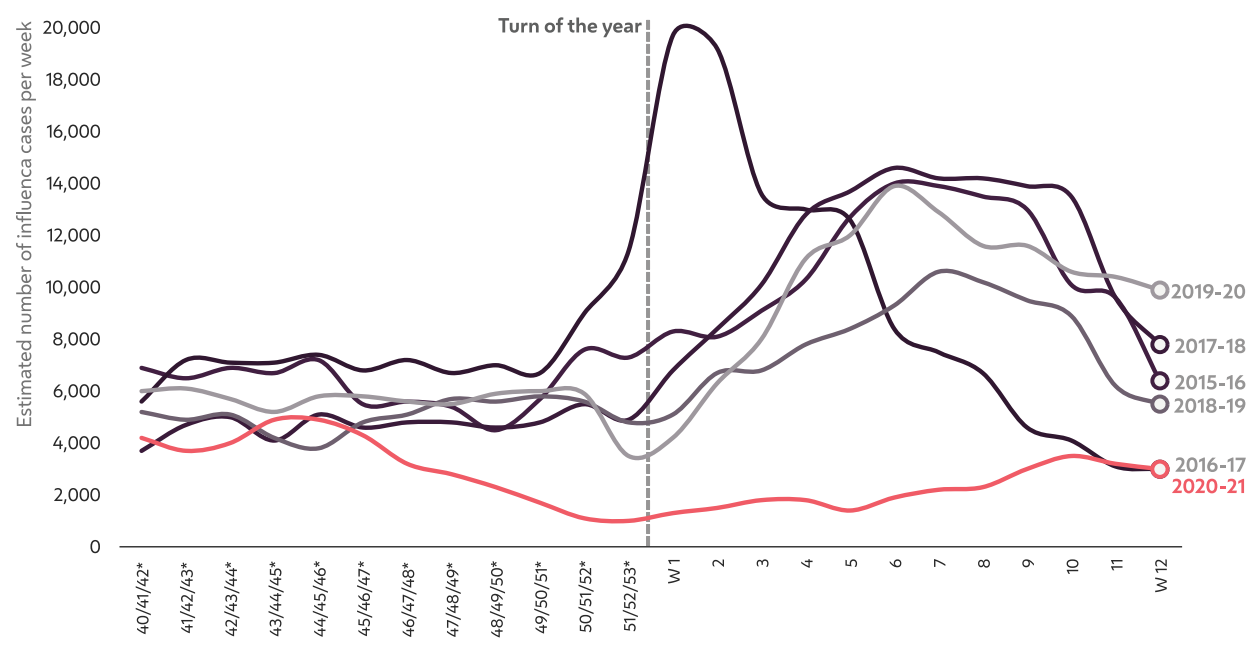

Notes: *Different number of calendar weeks per year.

Data Source: City of Vienna Health Service (2021).

2019/2020 flu season ended prematurely. ${ }^{13}$ Between week 12-2020 and week 182020, the numbers of COVID-19-related deaths started to increase, along with the positive deviation from the expected numbers of deaths. The pattern of COVID19-related deaths corresponding to unexpectedly high numbers of deaths was also visible during the start of the second wave of infections in autumn 2020. As Figure 7 shows, there was a small but consistent difference between COVID-19-related deaths and excess mortality until early December 2020 (i.e., around week 50-2020), which suggests that there was a slight under-reporting of COVID-19-related deaths in Austria. This pattern reversed during the last weeks of 2020, and from then on the number of COVID-19-related deaths exceeded the positive deviations from the expected number of deaths. These trends suggest that there was some over-reporting of COVID-19-related deaths. However, the change in the direction of the difference is not a surprise, given that our model is based on actual mortality between 2015 and 2019 (cf. Section 2.1). In this reference period, there were regular flu seasons during the winter months, including a severe influenza season during the winter of 2016/2017 (see also Figure 3). In the winter of 2020/2021, there was almost no flu season at all in Vienna (City of Vienna Health Service, 2021), in Austria

13 Figure 8 shows the weekly number of influenza and flu-like infections in Vienna and highlights the relatively low number of registered infections during the annual flu season in 2020/2021, which might be attributed to COVID-19-related changes in behaviour. This trend can be observed in most countries of the world, irrespective of the government-mandated restrictions (WHO, 2021c). 
Figure 9:

Numbers of weeks with excess mortality in the age group 65 and older in Vienna and Austria's provinces since week 1-2007

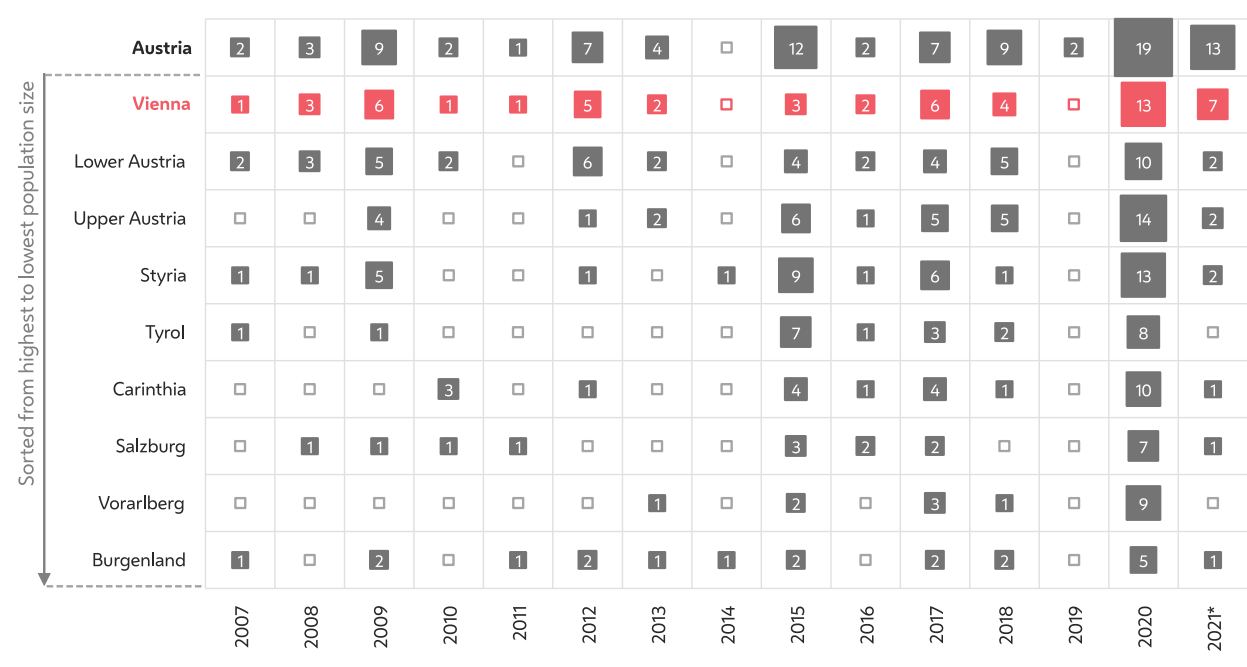

Notes: Preliminary count up to week 34-2021.

Data Source: Statistik Austria (2021c) and own calculations.

(AGES, 2021b) or in most other parts of the world (WHO, 2021b,c). Thus, it can be assumed that the expected overall number of deaths should be lower in 2020/2021 than it was in previous years. ${ }^{14}$ It remains unclear whether and, if so, to what extent the (slight) over-reporting of COVID-19-related deaths in Austria and Vienna or the absence of the annual flu season might have contributed to this change in the direction of the differences between registered COVID-19-related deaths and actual excess mortality at the turn of the year 2020/2021.

Finally, we looked at weekly mortality trends in Vienna, and compared them with trends in other Austrian provinces. The time series of our excess mortality model allows for the analysis of mortality trends at the spatial level of Austrian provinces from 2007 onwards. Figure 9 shows the number of weeks in which excess mortality can be observed among people aged 65 years and older (who are, in general, the age group most likely to be affected by excess mortality) in Austria and its nine provinces. Since 2007, there was just a single year (i.e., 2014) when there was no week in which this particular age group was affected by excess mortality at the national level. The visualisation, which is sorted by the population size of the provinces, again illustrates the sensitivity of the excess mortality model to population size (and the corresponding number of events), as

14 Austrian influenza monitoring by AGES (2021b): https://www.ages.at/themen/krankheitserreger/ grippe/saison-202021/ (retrieved 27 April 2021). 
Figure 10:

Deviations of the weekly and cumulative numbers of reported deaths from the predicted values* in Austria's provinces since week 1-2020

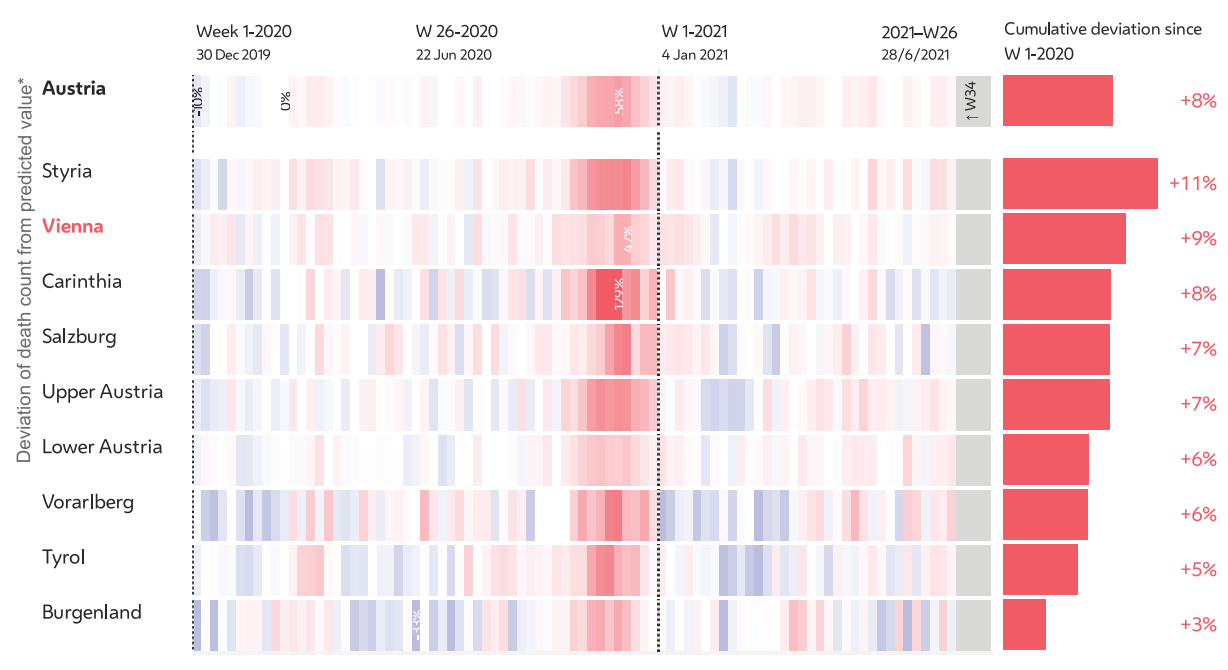

Notes: Preliminary data: Data for the two most recent weeks are partially estimated. *Predicted values are based on mortality in 2015-2019, current population size and structure and trends in life expectancy; deaths abroad are not included.

Data Source: Statistik Austria (2021c) and own calculations.

it shows that the magnitude of the deviation of the numbers of actual deaths from the predicted numbers of deaths is comparable only between provinces with similar population sizes (e.g., Vienna and Lower Austria or Vorarlberg and Burgenland). The visualisation also clearly indicates that in Austria as a whole and in all nine provinces, the period with by far the most weeks of excess mortality was during the COVID-19 pandemic in 2020. ${ }^{15}$

To assess the differences and the similarities in the impact of excess mortality across all nine Austrian provinces during the COVID-19 pandemic, we examined the developments in the weekly numbers of deaths since the beginning of 2020 . More precisely, we analysed the deviations of the actual weekly numbers of deaths from the median of the expected numbers of deaths (as predicted by our model). Figure 10 illustrates the course of the pandemic by indicating the direction of the deviation of the actual from the expected weekly numbers of deaths in Austria and its provinces since week 1-2020. Tyrol was more affected than other Austrian

15 Our analyses only include data until week 34-2021 (Monday, 23 August to Sunday, 28 August 2021). Therefore, the number of weeks with excess mortality in 2021 cited in this paper is still preliminary, as the total number cannot be assessed before early 2022 . 
provinces by excess mortality during the first wave. During the second wave, the COVID-19-related death toll was much higher and affected all Austrian provinces, though the provinces that were hardest hit during this period were Styria and Carinthia.

Figure 10 also shows the cumulative deviation of the actual from the expected number of deaths (all ages) by province between week 1-2020 and week 34-2021 (which corresponds to the end of August 2021). Across the entire observation period, the province of Styria experienced the greatest cumulative deviation from the expected number of deaths $(+11 \%)$. The provinces with the lowest cumulative excess mortality levels were Tyrol $(+5 \%)$ and Burgenland $(+3 \%)$; while Vienna $(+9 \%)$, Carinthia $(+8 \%)$ and Salzburg $(+7 \%)$ had cumulative excess mortality levels that were around the level for Austria as a whole $(+8 \%)$.

\section{Discussion}

Our analysis of weekly mortality in Austria and its nine provinces since 2007 (until week 34-2021) showed that there was a significant increase in the number of deaths during the COVID-19 pandemic. We developed an excess mortality model that was sensitive to the seasonality of mortality, as well as to changes in population size and age structure (with respect to the reference period). This model allowed us to quantify excess mortality for the age groups 0 to 64 years and 65 years and older at the spatial level of the Austrian provinces.

Our findings clearly indicate that during our study period, the elderly population (aged 65 years and older) was the most affected by excess mortality, not only during the COVID-19 pandemic, but also during summer heat waves and winter flu seasons (Fouillet et al., 2008; Pascal et al., 2018; Phu Pin et al., 2012). In addition, our analysis of excess mortality in Vienna and in the other Austrian provinces during the COVID-19 pandemic period (i.e., week 1-2020 to week 34-2021) uncovered regional differences in the extent of the COVID-19-related peaks in excess mortality. We found that in general, the regional mortality trends in the Austrian provinces followed the national pattern of the course of the (three) observed waves of COVID-19 infections. Our results showed that overall, the numbers of registered COVID-19 deaths in Austria matched the extent of the excess mortality, as quantified by our model.

A methodological challenge researchers face when conducting regional analyses is the sensitivity to small numbers. This problem also affected our analysis of excess mortality in Austrian provinces, as we observed that smaller numbers of events resulted in broader and less continuous prediction intervals. This issue was especially apparent for provinces such as Burgenland and Vorarlberg, which had fewer than 6,000 reported deaths (from all causes) each during the observation period of more than one and a half years (week 1-2020 until week 34-2021). Thus, it would not be feasible to further disaggregate the analysis of excess mortality in 
Austrian provinces using smaller age groups, or to apply the method to even smaller administrative areas.

Our comparison of excess mortality during the COVID-19 pandemic in Vienna and Austria demonstrated the importance of performing analyses at the sub-national level in order to shed light on within-country heterogeneities. To compare the impact of COVID-19 on mortality in Vienna with that in other metropolises, it would be necessary to look beyond Austria. Regional comparative analyses at the European level (Goujon et al., 2021; Schöley, 2021; EuroMOMO, 2021) are still limited, since Eurostat does not (yet) provide up-to-date mortality data for European cities and regions with a level of demographic detail similar to the level we used in our analysis (based on data provided by Statistik Austria). With respect to further research, we are currently investigating the availability of such data from European cities, which would allow us to analyse the specific characteristics of COVID-19-related excess mortality in the urban context. Future analysis by Statistics Vienna will also focus on excess mortality during summer heat waves, as well on other factors that affect mortality in Vienna.

\section{Acknowledgments}

This article has greatly benefited from the contributions and support of our colleagues at the City of Vienna, especially Daniel Jost and the Head of Department Peter Wieser at the City of Vienna's Department for Economic Affairs, Labour and Statistics (MA 23). We are grateful for the support in our efforts to provide quantitative evidence on the effects of COVID-19 on overall mortality by the Administrative Group for Finance, Business, Labour, International Affairs and Vienna Public Utilities (GFW) and its Executive City Councillor, Peter Hanke, and his staff at the City of Vienna. Our analyses relied on data from the Austrian Population Register (POPREG) and the Register of Vital Statistics (ZPR) provided by Statistik Austria's Alexander Wisbauer and colleagues. In the development of our methodology, we have received valuable support from our colleague Christoph Junker at the Swiss Federal Statistical Office (BFS), as well as from Johannes Klotz.

\section{ORCID}

Markus Speringer (D) https://orcid.org/0000-0001-7698-2838

\section{References}

Aburto, J., Kashyep, R., Schöley, J., Angus, C., Ermisch, J., Mills, M., and Dowd, J. (2021). Estimating the burden of the COVID-19 pandemic on mortality, life expectancy 
and lifespan inequality in England and Wales: A population-level analysis. Journal of Epidemiological Community Health, 75(8), 735-740. https://doi.org/10.1136/jech-2020215505

AGES - Österreichische Agentur für Gesundheit und Ernährungssicherheit GmbH, eds. (2021a). AGES Dashboard COVID 19. Datenstand des Epidemiologischen Meldesystems. Dataset. Retrieved 13 September 2021, from https://covid19-dashboard.ages.at

AGES - Österreichische Agentur für Gesundheit und Ernährungssicherheit GmbH, eds. (2021b). Grippe. Retrieved 1 April 2021, from https://www.ages.at/themen/ krankheitserreger/grippe/

Aron, J., Muellbauer, J., Giattino, C., and Ritchie, H. (2020). A pandemic primer on excess mortality statistics and their comparability across countries. Our World in Data, 29 June 2020. University of Oxford. https://ourworldindata.org/covid-excess-mortality

Bauer, R., Frühwirt, P., Jost, D., Seidl, R., Speringer, M., and Trautinger, F. (2021a). Vienna Mortality Monitoring 2007-2020. wien1x1.at - Die Stadt. Einfach erklärt., 28 June 2020. Statistics Vienna, City of Vienna. https://wien1x1.at/site/mortalitymonitor

Bauer, R., Frühwirt, P., Jost, D., Seidl, R., Speringer, M., and Trautinger, F. (2021b). Mortality monitoring in Austria's provinces since 2020. wien1xl.at - Die Stadt. Einfach erklärt., 28 June 2020. Statistics Vienna, City of Vienna. https://wien1x1.at/site/mortality-provinces

BFS - Federal Statistical Office, Switzerland (2020a). Mortality, causes of death. Retrieved 29 January 2021, from https://www.bfs.admin.ch/bfs/en/home/statistics/health/state-health/ mortality-causes-death.html

BFS - Federal Statistical Office, Switzerland. (2020b). Official statistics on deaths, causes of death and notifiable diseases. Methodological explanations. Federal Statistical Office, Neuchâtel. https://www.bfs.admin.ch/bfs/de/home/statistiken/gesundheit/ gesundheitszustand/sterblichkeit-todesursachen.assetdetail.12967241.html

BMSGPK - Bundesministerium für Soziales, Gesundheit, Pflege und Konsumentenschutz, eds. (2021). COVID-19 Schutzimpfungen - Eingetragene Impfungen im e-Impfpass. Die Zeitreihe der eingetragenen Impfungen in den e-Impfpass seit dem 10.01.2021. Österreichisches COVID-19 Open Data Informationsportal. Retrieved 13 September 2021, from https://www.data.gv.at/katalog/dataset/covid-19-schutzimpfungen-eingetrageneimpfungen-im-e-impfpass

CDC - Centers for Disease Control and Prevention. (2021). Excess Deaths Associated with COVID-19. Provisional Death Counts for Coronavirus Disease (COVID-19). Retrieved 26 August 2021, from https://www.cdc.gov/nchs/nvss/vsrr/covid19/excess_deaths.htm

City of Vienna Health Service. (2021). Grippemeldedienst der Stadt Wien - Aktuelle Grippestatistik. Health Service, City of Vienna. Retrieved 31 March 2021, from https: //www.wien.gv.at/gesundheit/einrichtungen/grippemeldedienst/

Destatis - Federal Statistical Office of Germany. (2021). Sterbefallzahlen und Übersterblichkeit. Retrieved 13 September 2021, from https://www.destatis.de/DE/Themen/ Querschnitt/Corona/Gesellschaft/bevoelkerung-sterbefaelle.html

EuroMOMO - European Mortality Monitoring Project. (2021). Graphs and maps. Retrieved 13 September 2021, from https://www.euromomo.eu/graphs-and-maps\#excess-mortality Eurostat - European Statistical Office. (2021). Excess mortality - statistics. Retrieved 13 September 2021, from https://ec.europa.eu/eurostat/statistics-explained/index.php?title= Excess_mortality_-_statistics 
Fouillet, A., Rey, G., Wagner, V., Laaidi, K., Empereur-Bissonnet, P., Le Tertre, A., Frayssinet, P., Bessemoulin, P., Laurent, F., De Crouy-Chanel, P., Jougla, E., and Hémon, D. (2008). Has the impact of heat waves on mortality changed in France since the European heat wave of summer 2003? A study of the 2006 heat wave. International Journal of Epidemology, 37(2), 309-317. https://doi.org/10.1093/ije/dym253

Frühwirt, P., and Seidl, R. (2020). Prognoseintervall Sterblichkeit (Methodendokumentation). MA43, Vienna. https://wien1x1.at/wp-content/uploads/sites/9/2020/05/ma23-methodikuebersterblichkeit.pdf

Ghislandi, S., Muttarak, R., Sauerberg, M., and Scotti, B. (2021). Human costs of the first wave of the COVID-19 pandemic in the major epicentres in Italy. Vienna Yearbook of Populations Research, 20. https://doi.org/10.1553/populationyearbook2022.res2.1

Giattino, C., Ritchie, H., Roser, M., Ortiz-Ospina, E., and Hasell, J. (2021). Excess mortality during the Coronavirus pandemic (COVID-19). Our World in Data. Retrieved 5 May 2021, from https://ourworldindata.org/excess-mortality-covid

Google LLC. (2021). Mobilitätsbericht zur Coronakrise: Österreich. So haben sich die Bewegungsmuster der Gesellschaft durch die Coronakrise verändert. https://www.gstatic. com/covid19/mobility/2021-04-29_AT_Mobility_Report_de.pdf

Goujon, A., Natale, F., Ghio, D., and Conte, A. (2021). Demographic and territorial characteristics of COVID-19 cases and excess mortality in the European Union during the first wave. Journal of Population Research. https://doi.org/10.1007/s12546-021-09263-3

ISO - International Organization for Standardization. (2019a). Data and time -Representation of information interchange - Part 1: Basic rules. International Standard ISO 8601-1:2019. https://www.iso.org/obp/ui/\#iso:std:iso:8601:-1:ed-1:v1:en

ISO - International Organization for Standardization. (2019b). Data and time Representation of information interchange - Part 2: Extensions. International Standard ISO 8601-2:2019. https://www.iso.org/obp/ui/\#iso:std:iso:8601:-2:ed-1:v1:en

Kelly, H. (2011). The classical definition of a pandemic is not elusive. Bulletin of the World Health Organization, 2011(89), 540-541. https://doi.org/10.2471/blt.11.088815

Nivette, A., Dibeaud, D., Murray, A., Steinhoff, A., Bechtiger, L., Hepp, U., Shanahan, L., and Eisner, M. (2021). Non-compliance with COVID-19-related public health measures among young adults in Switzerland: Insights from a longitudinal cohort study. Social Science $\mathcal{E}$ Medicine, 268, Article 113370. https://doi.org/10.1016/j.socscimed.2020.113370

Mallapatty, S. (2020). The coronavirus is most deadly if you are older and male - new data reveal the risks. Nature, 585, 16-17. https://doi.org/10.1038/d41586-020-02483-2

ORF - Austrian Broadcasting Corporation. (2021a). CoV: Mehr Unfälle von Kindern im Haushalt. ORF.at, 13 January 2021. https://wien.orf.at/stories/3084713

ORF - Austrian Broadcasting Corporation. (2021b). Gewalt in Familien nimmt zu. ORF.at, 19 January 2021. https://ooe.orf.at/stories/3085573/

Pascal, M., Wagner, V., Corso, M., Laaidi, K., Ung, A., and Beaudeau, P. (2018). Heat and cold related-mortality in 18 French cities. Environmental International, 121(1), 189-198. https://doi.org/10.1016/j.envint.2018.08.049

Phu Pin, S., Golmard, J., Cotto, E., Rothan-Tondeur, M., Chami, K., and Piette, F. (2012). Excess winter mortality in France: influence of temperature, influenza like illness, and residential care status. Journal of the American Medical Directors Association, 13(3), 309.e1-309.e7. https://doi.org/10.1016/j.jamda.2011.06.005 
Porta, M. (2014). A dictionary of epidemiology. Oxford University Press. https://doi.org/10. 1093/acref/9780199976720.001.0001

RKI - Robert Koch Institut. (2021). Epidemiologischer Steckbrief zu SARS-CoV-2 und COVID-19. Retrieved 9 March 2021, from https://www.rki.de/DE/Content/InfAZ/N/ Neuartiges_Coronavirus/Steckbrief.html;jsessionid=BB441A3D45D7557A334B2EEB20 BAB854.internet061?nn=13490888\#doc13776792bodyText5

Ritchie, H., Ortiz-Ospina, E., Beltekian, D., Mathieu, E., Hasell, J., Macdonald, B., Giattino, C., Appel, C., and Roser, M. (2021). COVID-19: Google Mobility Trends. How has the pandemic changed the movement of people around the world? Our World in Data. Retrieved 15 April 2021, from https://ourworldindata.org/covid-google-mobility-trends

Roser, M., Ritchie, H., Ortiz-Ospina, E., and Hasell, J. (2020). Coronavirus Pandemic (COVID-19). Our World in Data. Retrieved 18 February 2021, from https://ourworldindata. org/coronavirus

Schöley, J. (2021). Robustness and bias of European excess death estimates in 2020 under varying model specifications. MedRxiv. https://doi.org/10.1101/2021.06.04.21258353

Prlić, A. (2021). Corona-Pandemie lässt die Suizidrate steigen. Salzburger Nachrichten, 7 January 2021. https://www.sn.at/salzburg/chronik/corona-pandemie-laesst-die-suizidratesteigen-98029291

Statistics Vienna. (2021a). Mobility trends in European cities during the COVID-19 pandemic. wien1x1.at - Die Stadt. Einfach erklärt, 15 July 2021. Statistics Vienna, City of Vienna. https://wien1x1.at/mobility-covid/

Statistics Vienna. (2021b). Wien wächst moderat weiter: Bevölkerungsentwicklung 2020 (vorläufige Daten). wien 1x1.at - Die Stadt. Einfach erklärt, 29 January 2021. Statistics Vienna, City of Vienna. https://wien1x1.at/site/bevoelkerungsentwicklung-2020

Statistics Vienna. (2021c). Data monitor: Mortality in European countries and cities since (2015). wien1x1.at - Die Stadt. Einfach erklärt, 27 August 2021. Statistics Vienna, City of Vienna. https://wien1x1.at/site/mortalitaet-europa

Statistics Vienna. (2021d). Tatsächliche und erwartete wöchentliche Todesfälle seit 2007 in Österreichs Bundesländern (ohne Todesfälle im Ausland). Retrieved 13 September 2021, from https://www.wien.gv.at/statistik/ogd/mortalitaet-woechentlich.csv

Statistik Austria. (2020a). Mehr als die Hälfte der SARS-CoV-2-Infektionen kurz vor dem zweiten Lockdown sind behördlich nicht erfasst. Press Release. Retrieved 26 November 2020, from https://www.statistik.at/web_de/presse/124846.html

Statistik Austria. (2020b). Jeder dritte Verkehrstote im 1. Halbjahr 2020 aufgrund nicht angepasster Geschwindigkeit; mehr Radfahrerinnen und Radfahrer verunglückt. Press Release. Retrieved 22 October 2020, from http://www.statistik.at/web_de/presse/124560. html

Statistik Austria. (2021a). Bevölkerung zu Jahresbeginn gem. bevölkerungsstatistischer Datenbank (POPREG).

Statistik Austria. (2021b). Statistik der natürlichen Bevölkerungsbewegung gem. Zentralem Personenstandsregister (ZPR).

Statistik Austria. (2021c). Gestorbene in Österreich (ohne Auslandssterbefälle) ab 2000 nach Kalenderwoche. Retrieved 13 September 2021, from https://data.statistik.gv.at/web/meta. jsp?dataset=OGD_gest_kalwo_GEST_KALWOCHE_100 
Statistik Austria. (2021d). Lebenserwartung für ausgewählte Altersjahre 1868/71 bis 2010/12 sowie 1951 bis 2020. Retrieved 28 August 2021, from http://www.statistik.at/web_de/ statistiken/menschen_und_gesellschaft/bevoelkerung/sterbetafeln/index.html

The Economist. (2021). The pandemic's true death toll. Our daily estimate of excess deaths around the world. Retrieved 3 September 2021, from https://www.economist.com/graphicdetail/coronavirus-excess-deaths-estimates

WHO - World Health Organization. (2013). WHO Pandemic Phase Descriptions and Main Actions by Phase. https://www.who.int/influenza/resources/documents/pandemic_phase_ descriptions_and_actions.pdf

WHO - World Health Organization. (2020). WHO Director-General's opening remarks at the media briefing on COVID-19 - 11 March 2020. https://www.who.int/directorgeneral/speeches/detail/who-director-general-s-opening-remarks-at-the-media-briefingon-covid-19-11-march-2020

WHO - World Health Organization. (2021a). Past pandemics. https://www.euro.who.int/en/ health-topics/communicable-diseases/influenza/pandemic-influenza/past-pandemics

WHO - World Health Organization. (2021b). Influenza update No. 390. 29 March 2021. https://www.who.int/publications/m/item/influenza-update-n-390

WHO - World Health Organization. (2021c). Influenza - FluNet. Retrieved 29 April 2021, from https://www.who.int/tools/flunet

Open Access This article is published under the terms of the Creative Commons Attribution 4.0 International License (https://creativecommons.org/licenses/by/4.0/) that allows the sharing, use and adaptation in any medium, provided that the user gives appropriate credit, provides a link to the license, and indicates if changes were made. 